\title{
Synthesis of a novel green carbon dots as a bioimaging agent and a drug delivery system for enhanced antioxidant and antibacterial efficacy
}

Neeraj Tejwan

Shoolini University

Mousumi Kundu

Bose Institute Division of Molecular Medicine

Anirudh Sharma

Shoolini University

Joydeep Das

Shoolini University

Parames C Sil ( $\nabla$ parames@jcbose.ac.in )

Bose Institute https://orcid.org/0000-0003-0190-5904

\section{Research}

Keywords: Antioxidant, Antibacterial, Drug delivery, Green carbon dots, Rutin, Reactive oxygen species

Posted Date: May 19th, 2020

DOI: https://doi.org/10.21203/rs.3.rs-28922/v1

License: (c) (i) This work is licensed under a Creative Commons Attribution 4.0 International License. Read Full License 


\section{Abstract \\ Background}

Now-a-days, synthesis of carbon dots (CDs) from renewable sources has attracted considerable attention due to their wide spread availability, lower cost, higher aqueous solubility and more biocompatibility. Here, we have synthesized water soluble CDs from the root extract of red Korean ginseng via simple microwave irradiation. The CDs were further loaded with a natural flavonoid, rutin, to check its efficacy as a drug delivery system.

\section{Result}

The CDs showed a size distribution between 1-4 nm and excitation-dependent fluorescence emission, and could be used as a bio-imaging agent. The CDs showed a drug loading content of $14 \%$ and a sustained drug release behavior at physiological conditions. CDs showed excellent free radical scavenging activity both in cell free systems and intra-cellular conditions. Besides, loading with the drug further improved the intra-cellular radical scavenging activity. The CDs and the nanohybrids also showed very little toxicity upto the concentration of $100 \mu \mathrm{g} / \mathrm{mL}$ in normal kidney epithelial cells. The CDs and the nanohybrids also showed a dose-dependent antibacterial effect against both gram negative as well as gram positive bacteria.

\section{Conclusion}

Our synthesized green CDs can be considered as a promising candidate for the biomedical applications due to its facile synthesis, low cytotoxicity, excellent fluorescent properties and potential as drug delivery systems.

\section{Background}

Nanoparticle technology or nanotechnology is the study of nanomaterials in the field of electronics, medicine and agriculture. Carbon is the most abundant material on the earth having various allotropes like diamond, fullerene and graphite. Nanodiamonds, fullerenes, carbon dots (CDs), graphenes and carbon nanofibers are the new class of carbon nanomaterials, and have attracted much attention in the field of nanotechnology. CDs are the newly discovered member among the family with size less than $10 \mathrm{~nm}$ [1]. These nanomaterials are enriched with superior properties like excellent quantum yield, superior biocompatibility, good water solubility, higher degree of cell permeability and low cytotoxicity [2] which make them useful to be applied in the fields of biology and medicine [3]. CDs can be synthesized using various chemical and natural precursors via both top down as well as bottom up approaches. However, most of the researchers are widely using chemical precursors to synthesize CDs [4, 5]; therefore, there is much need of using eco-friendly techniques and sources to synthesize CDs in order to avoid their 
adverse effects. Some of the researchers have started using natural precursors for the synthesis of CDs due to their high renewability, low cost, and better biocompatibility. Various sources like plant materials, beverages, fruits and vegetables have been used to synthesize carbon dots [6]. Among those precursors, researchers are focusing more on the plant derived CDs.

Since ancient times, plants have not only been used as a food source but also been used to treat various diseases; therefore, several herbal medicines have been considered as the traditional methods of remedy $[7,8]$. Sometimes, the plant extract shows more efficacy and low toxicity in comparison to the commercial drugs [9]. Plants are enriched with different secondary metabolites such as flavonoids, glycosides, tannins, alkaloids, terpenoids etc which are responsible for showing their medicinal properties [10]. Extraction of the biologically active compounds from plants depend on the solvent used in the extraction procedure [11]. Different solvents such as alcohols, ether, ethyl acetate, chloroform and water are commonly used for the extraction purpose, and obviously water is the safest one among them [12]. Therefore, researchers are now showing their efforts for synthesizing CDs from the aqueous extract of several medicinal herbs [13]. Ginseng is one of the among medicinal herbs [14, 15]; therefore, we used the aqueous root extract of red Korean ginseng for the synthesis of CDs.

Panax ginseng Meyer, also called Korean ginseng is a plant which has been used as the traditional medicinal herb in the eastern Asian countries such as Korea, Japan and China [16, 17]. When the fresh Korean ginseng becomes red in color upon heating, it is called red Korean ginseng (RKG) [18]. The main constituents of RKG are ginsenosides, flavones, amino acids, acetylenic compounds, pyran derivatives and peptide glycans [19]. Ginsenosides have various medicinal properties like anticancer, antioxidant, antibacterial, anti-inflammatory, anti-diabetic, anti-stress, and anti-apoptotic [20]. Besides, RKG has also been widely studied and used for the treatment or improving the conditions of the various human disease $[21,22]$. However, most of the researchers have used RKG extract for the synthesis of some inorganic nanoparticles $[23,24]$ and only one report showed the use of ginsenosides for the preparation of CDs with anticancer potential [25].

Recently CDs have attracted the attention of researchers as a drug delivery system [26, 27] to increase the bioavailability of the drugs into the target organs while reducing its adverse effects to normal tissue. CDs have high surface area with $\mathrm{sp} 2$ core within it, and can conjugate various hydrophobic biomolecules via $\pi-\pi^{*}$ stacking or electrostatic interactions, thereby increasing their solubility in the aqueous media $[2,28]$. Besides, drugs can also be conjugated via covalent bonding with the functional groups present on the surface of $\mathrm{CDs}$. Furthermore, the drug delivery pathway can also be tracked due to the fluorescent nature of the CDs [29]. However, there is only few studies showing the use of CDs as a drug delivery system as most of the studies have focused on its optical properties [2, 30, 31].

In the present study, for the first time, we have synthesized a novel green CDs from aqueous root extract of RKG using microwave assisted heating and checked their potentials to be used as an antioxidant, antibacterial and bioimaging agents. Besides, we have also tested whether those CDs could be used as a drug delivery system for a hydrophobic natural flavonoid, rutin. Rutin is an important part of our regular 
diet and has profound nutraceutical benefits. It is abundantly found in the several vegetables and fruits such as, asparagus, buckwheat, figs, apple, grapes, plum. orange, and also found in some beverages such as green tea, black tea and elderflower tea [32]. Rutin exhibits multiple pharmacological actions and hence can be used for the treatment of several diseases like hypertension, cancer, hypercholesterolemia, diabetes, etc. Besides, it is also well-known for its cytoprotective, antioxidant, antibacterial, anticarccinogenic, neuroprotective, vasoprotective and cardioprotective activities [33]. However, the pharmacological actions of rutin are greatly limited by their low bioavailability due to poor aqueous solubility and low cell permeability [34]. In order to overcome those limitations, CDs were used as drug delivery vehicle to improve its pharmacological actions. Since both ginseng and rutin possess antioxidant \& anti-bacterial activities; therefore, we hypothesized that the nanohybrids (CDs-RUT) would exhibit higher antioxidant and antibacterial activities compared with free rutin by increasing the hydrophilicity and pharmacological actions of the hydrophobic drug.

\section{Methods}

\section{Materials}

Potassium ferricyanide, trichloroacteic acid, ferric chloride, acetate buffer, hydrogen peroxide, hydrochloric acid, rutin, ascorbic acid, sodium hydroxide, and dimethyl sulphoxide were purchased from Loba Chemie Pvt. Ltd. (Maharashtra, India), while other reagents, such as ammonium molybdate, ferrous sulphate (96\%), 1,1-diphenyl-2-picrylhydrazyl, monobasic and dibasic potassium phosphates were obtained from Central Drug House Pvt. Ltd. (New Delhi, India). Red Korean Ginseng (RKG) was purchased online from amazon.in. All the chemicals were used without further purification. Millipore system purified deionized water of conductivity $18 \Omega \mathrm{cm}^{-1}$ has been used in this experiment.

\section{Synthesis of carbon dots (CDs)}

CDs were synthesized from the aqueous root extract of red Korean Ginseng (RKG) by using an efficient, economic and one-step microwave assisted heating method. The extract was heated in a domestic microoven (IFB, Bangalore, India) with a tunable power of $700 \mathrm{~W}$ having frequency of $2450 \mathrm{MHz}$. We have heated the extract for 2 minutes in every cycles for a total 7 cycles with cooling intervals of 2 minutes after each cycle. Then, the formed CDs were suspended in water, dialysed with a 3500 Da MWCO membrane and lyophilized by employing Allied Frost lyophilizer (New Delhi, India) to get pure CDs in powder form.

\section{Loading of rutin (RUT) to CDs}

The aqueous solution of CDs was mixed with RUT dissolved in DMSO in a 1:1 mass ratio. The loading of RUT was done overnight with stirring at room temperature. After that the solution was dialyzed for 24 hours to remove the unbound drugs. The purified drug-loaded CDs or the nanohybrids (CDs-RUT) were lyophilized to get CDs-RUT in powder form. We have checked the drug loading content by thermo gravimetric analysis by a thermogravimetric analyser from Perkin Elmer company (Pyris 1; MA, USA). 


\section{Characterization of synthesized nanoparticles}

Transmission electron microscope (FEl; FP-5022 Tecnai G2 20 S-TWIN, USA) was used to know the size and morphology of the prepared particles. X-ray powder diffraction (XRD) pattern was analysed by Rigaku corporation (Smartlab 9 kW, Tokyo, Japan) X-ray diffractometer. The fluorescence and uv-vis spectra of the prepared particles were determined by using Thermo Fischer Scientific (Varioskan LUX 3020 - 561; Waltham, USA) spectrofluorimeter and Wensar (LMSP-UV1900; Chennai, India) spectrophotometer respectively. Fourier transform infrared (FTIR) instrument of Agilent technologies (L1600312; CA, USA) had been used to record the FTIR spectra in the range from 500 to $4000 \mathrm{~cm}^{-1}$. The hydrodynamic size of the synthesized nanoparticles was investigated by Dynamic Light Scattering instrument (Delsa, Nano C particle analyser; CA, USA).

\section{Time dependent drug release}

We have investigated the time dependent release of RUT from CDs-RUT nanohybrids in phosphate buffer saline (PBS) of $\mathrm{pH}=7.4$. We first dispersed the nanohybrids in the buffer with a concentration of $1 \mathrm{mg} / \mathrm{mL}$ by sonication. These solutions were then put into a dialysis membrane of $3500 \mathrm{Da}$ and the drug release was monitored by taking out the aqueous solution into which the dialysis membrane were floated under stirring condition at $37^{\circ} \mathrm{C}$. The drug release was checked after $6,12,24$, and 48 hours respectively by measuring the absorbance at $370 \mathrm{~nm}$ using an UV-Vis spectrophotometer.

\section{Fluorescent images of the synthesized nanoparticles}

The fluorescent images of the synthesized CDs have been taken by using Nikon fluorescence microscope. We first dispersed the CDs in PBS with a concentration of $1 \mathrm{mg} / \mathrm{mL}$ by sonication. After that, a drop of the above solution was placed on a clean glass slide. Bright field, FITC, DAPI and RITC filters were used to capture the image by using 20X objective lens of fluorescent microscope.

\section{Bacterial uptake of CDs}

CDs uptake was checked in the gram negative (E. coli) bacteria. At first, $10 \mu \mathrm{L}$ of inoculums were added into a fresh culture Luria-Bertani medium followed by addition of $50 \mu \mathrm{g} / \mathrm{mL}$ of CDs and incubated for 4 hrs in a shaker at $37^{\circ} \mathrm{C}$. After that the bacterial cells were washed with 1X PBS, placed on a glass slide, and the images were captured using the Bright field, FITC, DAPI and RITC filters by the fluorescent microscope.

\section{DPPH radical scavenging activity}

The ability of the ginseng derived CDs to neutralize the DPPH radicals has been examined by the method as published by Shimada et al. with some modifications [35]. The stock solution of the DPPH was prepared by dissolving $2 \mathrm{mg} \mathrm{DPPH}$ in $100 \mathrm{~mL}$ ethanol solution and was kept in the refrigerator until its use. Aqueous solutions of CDs with various concentrations ranging from $50 \mu \mathrm{g} / \mathrm{mL}$ to $600 \mu \mathrm{g} / \mathrm{mL}$ were mixed with a $2 \mathrm{~mL}$ DPPH solution and incubated for 30 minutes at $37^{\circ} \mathrm{C}$ in dark. After that the 
absorbance were measured at $517 \mathrm{~nm}$ and the results were presented as \% inhibition by using the formula;

$\%$ inhibition $=\left(A_{\text {control }}-A_{\text {sample }} / A_{\text {control }}\right) \times 100 \%$

\section{$\mathrm{H}_{2} \mathrm{O}_{2}$ scavenging activity}

The ability of CDs to scavenge $\mathrm{H}_{2} \mathrm{O}_{2}$ free radicals has been investigated by using the method as reported by Ruch et al. with minor modifications [36]. Various concentrations of ginseng derived CDs (50 $\mu \mathrm{g} / \mathrm{mL}-$ $700 \mu \mathrm{g} / \mathrm{mL}$ ) were mixed with $43 \mathrm{mM} \mathrm{H}_{2} \mathrm{O}_{2}$ in $1 \mathrm{M} \mathrm{PBS}$ and incubated for 10 minutes at $37^{\circ} \mathrm{C}$ in dark. $\mathrm{H}_{2} \mathrm{O}_{2}$ scavenging activity of $\mathrm{CDs}$ was evaluated by taking absorbance at $230 \mathrm{~nm}$ against the blank solution. \% scavenging activity was calculated by using the formula:

$\%$ inhibition $=\left(A_{\text {control }}-A_{\text {sample }} / A_{\text {control }}\right) \times 100 \%$

\section{Ferric reducing power assay}

Reducing power of the CDs was checked against ferric ions by the procedure reported by Vijayalakshmi and Rukmani [37]. $150 \mu \mathrm{L}$ CDs with different concentrations were mixed with $1 \mathrm{~mL}$ buffer $(\mathrm{pH}=6.6), 1 \mathrm{~mL}$ of ( $1 \%$ ) potassium ferricyanide and $1 \mathrm{~mL} 10 \%$ TCA, and then kept in an incubator for 20 minutes at $50{ }^{\circ} \mathrm{C}$. After that the solution was centrifuged at $3000 \mathrm{rpm}$ for 10 minutes and to the supernatant, $1 \mathrm{~mL}$ distilled water and $250 \mu \mathrm{L} 1 \% \mathrm{FeCl}_{3}$ were added. The mixture was again kept for another 10 minutes and the absorbance of the samples were measured at $700 \mathrm{~nm}$. In this assay, the colour of the samples became dark upon increasing the reduction of $\mathrm{Fe}^{3+}$ to $\mathrm{Fe}^{2+}$.

\section{Ferric reducing anti-oxidant potential}

Ferric reducing anti-oxidant potential of the CDs were investigated by the method reported by Ahmed at al. with slight changes [38]. At first the FRAP reagents were prepared by mixing $40 \mathrm{~mm}$ TPTZ, acetate buffer and $0.1 \% \mathrm{FeCl}_{3}$ in the ratio $1: 10: 1$ and then added to the $\mathrm{CDs}$ with different concentrations. After that the resultant mixture were kept in the incubator for 15 minutes at $50{ }^{\circ} \mathrm{C}$ in dark and measured the absorbance at $593 \mathrm{~nm}$. In this assay, $\mathrm{Fe}^{3+}$ transformed to $\mathrm{Fe}^{2+}$ which was confirmed by the blue-coloured product (Fe"l-TPTZ).

\section{Determination of intracellular Reactive Oxygenated Species (ROS) in normal cells}

To investigate the intracellular ROS level, the human normal kidney epethelial (NKE) cells were first exposed to $100 \mu \mathrm{g} / \mathrm{mL}$ of CDs, RUT and CDs-RUT nanohybrid for $12 \mathrm{hrs}$ followed by addition of tertiarybutyl hydroperoxide (TBHP) for 1 hrs. After that, cells were scraped, centrifuged for 5 minutes at the speed of $300 \mathrm{Xg}$ at room temperature, resuspended in PBS, and then incubated with the probe $\left(2,7^{\prime}\right.$ dichlorodihydrofluorescein diacetate) $\mathrm{H}_{2}$ DCFDA with a concentration of $2 \mu \mathrm{M}$ for 25 minutes at $37^{\circ} \mathrm{C}$. 
Finally, the green fluorescence intensity of the cells were checked by using a BD-FACS Calibur Flow Cytometry System using a bandpass filter of $525 \mathrm{~nm}$ [39].

\section{Cell viability assay}

The cytotoxicity of the CDs, RUT and CDs-RUT were measured against the human normal kidney epethelial (NKE) cells by standard MTT assay. Firstly, the cells were plated in a 96 well plate having density of $1.25 \times 10^{5}$ cells/well inside the incubator. After 24 hours of incubation under $5 \% \mathrm{CO}_{2}$ at $37^{\circ} \mathrm{C}$, cells were treated with different concentrations $(10-100 \mu \mathrm{g} / \mathrm{mL})$ of the CDs, RUT and CDs-RUT for 24 hours. $100 \mu \mathrm{L} /$ well of MTT with concentration of $0.5 \mathrm{mg} / \mathrm{mL}$ was added to the well after removing the media. At the end, $100 \mu \mathrm{L}$ of DMSO solution per well was added and incubated for another 4 hours. The absorbance was taken at $570 \mathrm{~nm}$ by using microtiter plate reader and the cell viability (\%) was calculated by using the formula: Cell viability $(\%)=\left(A_{\text {sample }} / A_{\text {control }}\right) \times 100 \%$

Where, $A_{\text {sample }}=$ Absorbance of the sample

$A_{\text {control }}=$ Absorbance of the control

\section{Antibacterial study}

Gram negative ( $E$. coli $)$ and gram positive (S. aureus) bacteria were used to check the dose dependent antibacterial activity of the CDs, RUT and CDs-RUT. This assay was performed according to the protocol mentioned in the report with slight modifications [40]. At first, $10 \mu \mathrm{L}$ of inoculums were added into a fresh culture medium. Then different concentrations $(0-200 \mu \mathrm{g} / \mathrm{mL})$ of CDs, RUT and CDs-RUT were added to the medium and incubated for $18 \mathrm{hrs}$ in a shaker at $37^{\circ} \mathrm{C}$. Luria-Bertani (LB) media consist of only particles are considered as blank whereas, LB with only inoculums is treated as controls. Finally, the growth of the bacteria was calculated by taking the absorbance at $600 \mathrm{~nm}$ by using a spectrophotometer. Minimum inhibitory concentration (MIC), i.e. the lowest concentration of any formulation to inhibit the complete growth of bacteria was calculated by checking the concentration of the nanoformulations at which the absorbance value was zero.

\section{Determination of intracellular ROS in bacteria}

To investigate the intracellular ROS level, the bacterial cells were first exposed to CDs, RUT and CDs-RUT nanohybrid for $18 \mathrm{hrs}$ with the concentrations of $100 \mu \mathrm{g} / \mathrm{mL}$. After that, cell suspension was centrifuged for 5 minutes at the speed of $300 \mathrm{Xg}$ at room temperature, resuspended in PBS, and then incubated with the probe $\left(2,7^{\prime}\right.$-dichlorodihydrofluorescein diacetate) $\mathrm{H}_{2}$ DCFDA with a concentration of $2 \mu \mathrm{M}$ for 25 minutes at $37^{\circ} \mathrm{C}$. Finally, the green fluorescence intensity of the cells was checked by using a spectrofluorimeter at an excitation wavelength of $495 \mathrm{~nm}$ and emission wavelength of $525 \mathrm{~nm}$ [39].

\section{Statistical analysis}

All the results have shown as mean \pm SD after performing each experiment at least three times. 


\section{Results}

\section{Synthesis and characterization of CDs}

First of all, we have synthesized CDs from the aqueous root extract of red Korean ginseng via microwave irradiation, then RUT was loaded onto the surfaces of CDs via non covalent $\pi-\pi^{\star}$ interactions and investigated their antioxidant and antibacterial effects (Scheme 1). TEM technique was used to determine the shape and size of the as synthesized CDs as displayed in (Fig. 1a). TEM study revealed that the CDs were spherical in size with an average size distribution between 1-4 nm (Fig. 1b). EDX analysis showed the presence of carbon, oxygen and nitrogen in the CDs (Fig. 1c), thereby indicating the presence of several $\mathrm{N}$ and O-containing functional groups. An XRD spectrum of the CDs has been shown in the Fig. 1d indicating their amorphous nature. The average hydrodynamic size of the synthesized CDs was found to be $13.94 \pm 1.13 \mathrm{~nm}$ and the size was further increased to $175.46 \pm 9.20 \mathrm{~nm}$ upon drug loading (Fig. 2a). The FTIR spectral data (Fig. 2b) depicted that the ginseng derived CDs showed the major peaks/bands at $3323 \mathrm{~cm}^{-1}, 2925 \mathrm{~cm}^{-1}, 1596-1700 \mathrm{~cm}^{-1}$ and $1017 \mathrm{~cm}^{-1}$ which corresponds to the $\mathrm{O}-\mathrm{H} / \mathrm{N}-\mathrm{H}$ stretching, $\mathrm{C}-\mathrm{H}$ stretching, $\mathrm{C}=\mathrm{O}$ or aromatic $\mathrm{C}=\mathrm{C}$ stretching and $\mathrm{C}-\mathrm{O}$ stretching respectively [41]. RUT showed several characteristic peaks of $\mathrm{O}-\mathrm{H}$ stretching, $\mathrm{N}-\mathrm{H}$ stretching, $\mathrm{C}=\mathrm{O}$ stretching, aromatic $\mathrm{C}=\mathrm{C}$ stretching, and $\mathrm{C}-\mathrm{O}$ stretching. The transmittance peaks of RUT loaded CDs were identical to those of pure RUT in the range of 500 to $1700 \mathrm{~cm}^{-1}$, indicating the successful loading of RUT onto CDs. Figure $2 c$ displayed the photographs of the freshly prepared aqueous solutions of CDs, RUT and CDsRUT. Results indicated that loading of RUT over CDs increased its aqueous solubility.

\section{Drug loading and time dependent drug release}

Drug loading content was found to be approximately $14 \%$ via TGA (Fig. 2 d). We have also checked the time dependent RUT release from the nanohybrids under physiological condition and at different intervals of time (Fig. 2e). We have found that the free drug concentration was increased in the suspension $(\mathrm{pH}=$ 7.4) with time, and the maximum drug concentration achieved was around $1.5 \mu \mathrm{g} / \mathrm{mL}$ after $48 \mathrm{hrs}$. After $48 \mathrm{hrs}$, there was no significant change in the release.

\section{Optical properties and bacterial imaging}

Figure 3a displayed the UV-Vis spectra of CDs, RUT and CDs-RUT. CDs showed the absorption peaks at $285 \mathrm{~nm}$ and $340 \mathrm{~nm}$ due to $\pi-\pi^{\star}$ and $n-\pi^{\star}$ transitions. Drug showed the characteristic peaks at $285 \mathrm{~nm}$ and $360 \mathrm{~nm}$. However, in the CDs-RUT, the parent peaks were shifted from their original positions due to the interactions between CDs and RUT.

The fluorescence spectra of the CDs were shown in the Fig. 3b. CDs showed an excitation-dependent fluorescence emission within the excitation range of 320 to $440 \mathrm{~nm}$. Maximum emission was observed when they were excited from 380 to $400 \mathrm{~nm}$. Fluorescence microscopic analysis has shown the intense blue, green and red colours coming from the CDs when excited at their respective excitation wavelength (Fig. 3c). Besides, we have also checked the CDs uptake in E. Coli via fluorescence microscopic analysis 
and we observed intensed blue, green and red fluorescence coming from the bacterial cells upon CDs treatment (Fig. $3 \mathrm{~d}$ ). These results are indicating the probable use of the CDs as bio-imaging agents.

\section{DPPH radical scavenging activity}

DPPH produces a dark purple colour in solution due to the extensive delocalization of the free radical, and the colour gets faded in presence of antioxidants which neutralise the free radicals. When the DPPH solution was incubated with increasing concentrations of $\mathrm{CDs}$, the colour intensity was gradually decreased, thereby revealing their antioxidant nature. We found that CDs showed $85.4 \%$ scavenging activity at the concentration of $600 \mu \mathrm{g} / \mathrm{mL}$ as shown in Fig. $4 \mathrm{a}$, and no significant changes were observed thereafter.

\section{$\mathrm{H}_{2} \mathrm{O}_{2}$ scavenging activity}

$\mathrm{H}_{2} \mathrm{O}_{2}$ is highly important radical that can be produced inside the cells. Intact $\mathrm{H}_{2} \mathrm{O}_{2}$ shows the absorbance peak at $230 \mathrm{~nm}$, the absorbance value gets decreased upon its conversion into $\mathrm{O}_{2}$ and $\mathrm{H}_{2} \mathrm{O}$ in presence of antioxidants. Our synthesized $\mathrm{CDs}$ have shown $77-87 \% \mathrm{H}_{2} \mathrm{O}_{2}$ scavenging activity within the concentration range of $50-700 \mu \mathrm{g} / \mathrm{mL}$ as depicted in Fig. $5 \mathrm{~b}$.

\section{Ferric reducing power assay}

The reducing power of any antioxidant can be determined by its electron donating ability to $\mathrm{Fe}^{3+}$ ions. When the test solution containing potassium ferricyanide was treated with CDs, it was reduced to potassium ferrocyanide which produced a dark green color in presence of $\mathrm{Fe}^{3+}$ ions. When the absorbance of the Prussian blue complex was measured, we found that CDs showed a concentrationdependent rise in color intensity upto a concentration of $1000 \mu \mathrm{g} / \mathrm{mL}$ (Fig. 4c).

\section{Ferric reducing antioxidant potential}

This is another method to check the electron donating ability of any antioxidant molecules via the reduction of $\mathrm{Fe}^{3+}$ to $\mathrm{Fe}^{2+}$. When $\mathrm{CDs}$ were added to (Fe $\mathrm{Fe}^{\mathrm{III}}-\mathrm{TPTZ}$ ), it was reduced to a blue-coloured product (Fell-TPTZ). We have also measured the absorbance of the complex formed, and observed that the colour intensity was increased with increasing concentration of the added CDs upto a concentration of 700 $\mu \mathrm{g} / \mathrm{mL}$ (Fig. 4d).

\section{Intracellular reactive oxidative species (ROS) scavenging activity}

Intracellular ROS levels were measured by using FACS analysis in the NKE cells. Cells were pre-treated with CDs, RUT and CDs-RUT for 18 hrs with the concentration of $40 \mu \mathrm{g} / \mathrm{mL}$ followed by treatment with TBHP for $1 \mathrm{hrs}$. We observed that TBHP exposure increased the intracellular ROS level as indicated by the increased fluorescence as compared to the control cells (Fig. 4e). However, pre-treatment with CDs, RUT and CDs-RUT reduced the ROS levels, thereby indicating their antioxidant nature (Fig. 4e). CDs-RUT showed the maximum level of ROS neutralization effect among the tree groups. 


\section{Cytotoxicity}

Cytotoxicity of the as prepared nanoformulations, viz CDs, RUT and CDs-RUT were checked in the NKE cells. The cells were treated with the nanoformulations within the concentration range from 10-100 $\mu \mathrm{g} / \mathrm{mL}$ for 24 hours, and the cell viability was measured by using MTT assay. We have observed that CDs were imparting very less toxicity and only around $15 \%$ cells underwent death at the maximum dose used (Fig. 4f). Similarly, RUT and CDs-RUT also did not cause any severe toxicity and more than $80 \%$ cells were alive at the maximum dose of treatment (Fig. 4f).

\section{Antibacterial Activity and ROS formation}

We have also checked the antibacterial effects of the CDs, RUT and CDs-RUT nanohybrids in both gram positive (S. aureus) and gram negative (E. Coli), bacteria. We have observed that although CDs and RUT alone could not significantly inhibit the bacterial growth, but the CDs-RUT nanohybrid showed a dosedependent synergistic effect in inhibiting the bacterial growth in both the stains (Fig. 5a \& b). We have also compared the MIC among the groups and the values are $1109.53,3576.25$ and $355.16 \mu \mathrm{g} / \mathrm{mL}$ for the gram positive bacteria and 1098.90, 3292.82 and $355.41 \mu \mathrm{g} / \mathrm{mL}$ for the gram negative bacteria for CDs, RUT and CDs-RUT treatment groups respectively (Fig. 5c).

Finally, we have checked whether the nanoformulations could induce increased ROS formation within the bacteria. We have observed that similar to the bacterial growth inhibition, CDs-RUT nanohybrids caused maximum ROS production among the treatment groups in both kinds of bacterial stains (Fig. $5 d \& \mathbf{e}$ ). CDs-RUT nanohybrids caused a 4.45 folds increase in ROS levels in the gram positive bacteria and 4.9 folds increase in ROS levels in gram negative bacteria with respect to the control groups.

\section{Discussion}

In the present study, we have prepared a novel biocompatible green CDs from the aqueous root extract of red Korean Ginseng and investigated its applications as a bioimaging agent as well as a drug carrier for the delivery of a hydrophobic bioactive flavonoid, rutin (RUT) for its increased antioxidant and antibacterial efficacy.

The as synthesized CDs were characterized by using various physical techniques such as TEM, DLS, EDX, XRD, and FTIR spectroscopy analyses. TEM images showed nearly spherical shape of the synthesized CDs with diameter within the range of 1-4 nm. However, the DLS data showed a slight increase in the size of CDs. TEM analysis is normally performed in dry and static form, but in DLS measurements, the hydrodynamic size of nanoparticles is investigated in hydrated form. Hence, the hydrodynamic diameter of those nanoparticles is higher than TEM size due to the extensive hydration/salvation [42]. The drug loading over CD surface was supported by the increased hydrodynamic size of the CDs-RUT nanohybrids in comparison to the CDs. The EDX spectrum of CDs revealed the presence of carbon, nitrogen and oxygen, while the XRD pattern showed their amorphous nature [43]. 
FTIR spectrum of the as prepared CDs-RUT nanohybrids showed several characteristic peaks of pure RUT in conjunction with $\mathrm{CDs}$, thereby further confirming the drug attachment onto the $\mathrm{CD}$ surface. $\mathrm{CDs}$ showed the major transmittance peak/bands at $3323 \mathrm{~cm}^{-1}, 2925 \mathrm{~cm}^{-1}, 1596-1700 \mathrm{~cm}^{-1}$ and $1017 \mathrm{~cm}^{-}$ ${ }^{1}$ which corresponds to the stretching vibrations of hydroxyl or amine groups, $\mathrm{C}-\mathrm{H}$ groups, $\mathrm{C}=\mathrm{O}$ and aromatic $\mathrm{C}=\mathrm{C}$ bonds, and $\mathrm{C}-\mathrm{O}$ bonds respectively [41]. Pure RUT showed peaks at $1652 \mathrm{~cm}^{-1}, 1504 \mathrm{~cm}^{-1}$ and $1358 \mathrm{~cm}^{-1}$ which could be the characteristic peaks of mixed $\mathrm{C}=\mathrm{O}$ and $\mathrm{C}=\mathrm{C}$ bonds, symmetric stretching vibrations of aromatic ring and $\mathrm{C}-\mathrm{O}$ stretching respectively [13]. Some transmittance peaks at $3621 \mathrm{~cm}^{-1}, 3419 \mathrm{~cm}^{-1}$ could be assigned to $\mathrm{O}-\mathrm{H}$ stretching while peaks at $2937 \mathrm{~cm}^{-1}, 2919 \mathrm{~cm}^{-1}$ might be due to the $\mathrm{C}-\mathrm{H}$ stretching [44].

Further the TGA was performed to check the amount of drug loaded onto the CD surface and it was found to be around $14 \%$ by weight. Later we have also checked whether the CDs-RUT nanohybrid could release the drug under physiological condition as the free form of any drug is required to show its pharmacological action. We have observed that the nanohybrid was broken down under physiological condition and leading to the release of RUT after $6 \mathrm{hrs}$. The concentration of the drug in the release media was around $1.3 \mu \mathrm{g} / \mathrm{mL}$ after $6 \mathrm{hrs}$ which is very close to the drug concentration $(1.5 \mu \mathrm{g} / \mathrm{mL})$ achieved after $48 \mathrm{hrs}$, thereby indicating a very fast release of the drug to show its quick pharmacological effects.

The optical properties of the CDs were evaluated via using UV-VIS and fluorescence spectroscopic as well as fluorescence microscopic analyses. CDs showed the characteristic absorption peaks due to the $\pi-\pi^{*}$ and $n-\pi^{\star}$ transitions at $285 \mathrm{~nm}$ and $340 \mathrm{~nm}$ respectively [45]. The CDs-RUT nanohybrid showed all the characteristic peaks of CDs and RUT with slight shifting due to overlap or interaction between the functional groups of CDs and RUT [46]. The fluorescence nature of the CDs was evaluated by analysing its fluorescence spectra and fluorescence microscopic analyses. CDs showed an excitation-dependent fluorescence emission with a red shift when the excitation wavelength changes from 320 to $440 \mathrm{~nm}$, and the maximum fluorescence intensity was observed when they were excited from 380 to $400 \mathrm{~nm}$. The CDs also showed blue, green and red fluorescence under ultra-violet, blue and green light excitation respectively, thereby indicating the probable use of the CDs as bioimaging agents [2]. We have further proved the possibility of using CDs for bacterial imaging using $E$. Coli which showed intensed blue, green and red fluorescence when incubated with CDs.

Next we have checked the free radical scavenging activities of the CDs in cell free system via DPPH radical and $\mathrm{H}_{2} \mathrm{O}_{2}$ scavenging activity as well as ferric reducing power and FRAP assay. CDs showed a dose-dependent DPPH radical and $\mathrm{H}_{2} \mathrm{O}_{2}$ scavenging activity. Besides, $\mathrm{CDs}$ exhibited a strong electron donating ability as indicated by the dose-dependent reduction of ferric to ferrous ions in presence of CDs. All these above results indicated that our synthesized CDs have profound antioxidant potentials due to its highly efficient electron donating or reducing ability. Inspired by its efficient antioxidant properties in cell free system, we have also checked whether it could show the equally efficient antioxidant properties within cells. For that, we have first pre-treated the human normal kidney epithelial cells with CDs followed by treatment with a known ROS inducer, TBHP. We have observed that CDs could inhibit the ROS 
formation to a larger extent induced by TBHP within the cells, thereby indicating its cellular antioxidant nature. Moreover, treatment with the CDs-RUT nanohybrids could almost neutralise the ROS and this effect is even higher than the free drug, RUT due to the combined effects of the CDs and drugs. These results indicated that the pharmacological actions of the drugs were retained even after release from the nanohybrids. Therefore, our synthesized CDs can not only strengthen the antioxidant defence mechanism of cells, but also increase the pharmacological actions of natural bioactive hydrophobic antioxidant molecules by increasing its hydrophilicity. Further, we have checked the maximum tolerated dose of the CDs and CDs-RUT nanohybrids in normal cells and we observed that the nanoformulations did not cause any severe toxicity and more than $80 \%$ cells were alive within the concentration range from $10-100$ $\mu \mathrm{g} / \mathrm{mL}$ when treated for 24 hours.

Finally, the antibacterial activities of the CDs and CDs-RUT nanohybrids were checked against both gram negative ( $E$. Coli $)$ and gram positive (S. aureus) bacteria. Antibacterial activity of the ginseng extracts has previously been reported [23, 24, 47]. Growth kinetic studies showed that CDs-RUT exhibited a synergistic growth inhibition against both the stains, although CDs and RUT alone did not show much effect on it. Further, the intracellular ROS levels were checked to investigate the mechanism behind the antibacterial effects of the nanoformulations $[36,48,49]$. We have observed that CDs could only enhance the ROS level twice compared to the control, whereas CDs-RUT exhibited 4-5 times enhancement in the ROS level within the bacteria. On the other hand, the free drug, RUT was least effective in inducing ROS. Therefore, our synthesized CDs could increase the pharmacological actions of the hydrophobic antibacterial molecules by increasing its hydrophilicity.

\section{Conclusion}

In conclusion, we have used a green and renewable source, viz aqueous root extract of red Korean ginseng to synthesize a biocompatible CDs by a facile, low cost microwave irradiation method without using any passivating agent. Due to the presence of $\mathrm{N}$ and $\mathrm{O}$-containing multifunctional groups, $\mathrm{CDs}$ were hydrophilic in nature. They showed multicolour emission (blue, green and red) when excited at ultraviolet, blue and green excitation light respectively. Our results also revealed that CDs have excellent antioxidant property due to its efficient electron donating ability, and scavenge ROS both in extracellular and intracellular conditions. Besides, CDs could also be used as a carrier for the delivery of hydrophobic bioactive molecules and increase their pharmacological actions (antioxidant, antibacterial) by increasing their hydrophilicity. Taken together, our synthesized green CDs can be considered as a promising candidate for the biomedical applications due to its facile synthesis, low cytotoxicity, excellent fluorescent properties and potential as drug delivery systems.

\section{Declarations}

\section{Availability of data and materials}




\section{Ethics approval and consent to participate}

Not applicable.

\section{Consent for publication}

Not applicable.

\section{Competing interests}

The authors declare that they have no competing interests.

\section{Funding}

Our research study did not receive any specific grant from funding agencies.

\section{Authors' contributions}

N.T, J.D. and P.C.S. designed the study; A.S. and N.T. characterized the nanoparticles; M.K. performed the biological experiments in cells; J.D. and P.C.S. supervised the study; A.S., N.T., M.K., J.D. and P.C.S. analyzed the data; N.T., J.D. and P.C.S. wrote the manuscript; All authors reviewed the manuscript.

\section{Acknowledgement}

Authors would like to thank the Shoolini University and Bose Institute for providing the instruments and lab facilities.

\section{References}

1. Jallel JA, Pramod K. Artful and multifaceted applications of carbon dot in biomedicine. J Control Release. 2018;269:302-21.

2. Tejwan N, Saha S, Das J. Multifaceted applications of green carbon dots synthesized from renewable sources. Adv Colloid interface Sci. 2020;275:102046.

3. Jhonsi MA, Ananth DA, Thilagar GN. Antimicrobial activity, cytotoxicity and DNA binding studies of carbon dots. Spectrochimi Acta A. 2018;196:295-302. 
4. Sharma A, Das J. Small molecules derived carbon dots: synthesis and applications in sensing, catalysis, imaging, and biomedicine. J Nanobiotechnology. 2019;17:92.

5. Thakur N, Manna P, Das J. Synthesis and biomedical applications of nanoceria, a redox active nanoparticle. J Nanobiotechnology. 2019;17:84.

6. Sharma V, Tiwari P, Mobin SM. Sustainable carbon-dots: recent advances in green carbon dots for sensing and bioimaging. J Mater Chem B. 2017;5:8904-24.

7. Ang-Lee MK, Moss J, Yuan CS. Herbal medicines and perioperative care. JAMA. 2001;286:208-16.

8. Kim MS, Lee Y, Sung GH, Kim JH, Park JG, Kim HG, Baek KS, Cho JH, Han J, Lee KH, Hong S, Kim JH, Cho JY. Pro-apoptotic activity of 4-isopropyl-2-(1-phenylethyl) aniline isolated from Cordyceps bassiana. Biomol Ther (Seoul). 2015;23:367-73.

9. Awaad AS, El-Meligy RM, Qenawy SA, Atta AH, Soliman GA. Anti-inflammatory, antinociceptive and antipyretic effects of some desert plants. J Saudi Chemical Soc. 2011;15:367-73.

10. Dahanukar SA, Kulkarni RA, Rege NN. Pharmacology of medicinal plants and natural products. Indian J Pharmacol. 2000;32:81-118.

11. Lalitha TP, Jayanthi P. Preliminary studies on phytochemicals and antimicrobial activity of solvent extracts of Eichhornia crassipes (Mart.). Solms Asian J Plant Sci Res. 2012;2:115-22.

12. Poulson $\mathrm{H}$, Preime H, Loft S. Role of oxidative DNA damage in cancer initiation and promotion. Euro J Cancer Preventive. 1998;7:9-16.

13. Rates SMK. Plants as source of drugs. Toxicon. 2001;39:603-13.

14. Yuan CS, Wei G, Dey L, Karrison T, Nahlik L, Maleckar S, Kasza K, Lee MA. Brief communication: American ginseng reduces warfarin's effect in healthy patients: a randomized, controlled trial. Ann Intern Med. 2004;141:23-7.

15. Shin BK, Kwon SW, Park JH. Chemical diversity of ginseng saponins from Panax ginseng. J Ginseng Res. 2015;39:287-98.

16. Ranjbar SH, Nayebi N, Larijani B, Abdollahi M. The efficacy and safety of herbal medicines used in the treatment of hyperlipidemia; a systematic review. J Gastroenterol. 2009;15:3073-85.

17. Lu JM, Yao Q, Chen C. Ginseng compounds: an update on their molecular mechanisms and medical applications. Curr Vasc Pharmacol. 2009;7:293-302.

18. Baeg IH, So SH. The world ginseng market and the ginseng (Korea). J Ginseng Res. 2013;37:1-7.

19. Choi KT. Botanical characteristics, pharmacological effects and medicinal components of Korean Panax ginseng CA Meyer. Acta Pharmacol Sin. 2008;29:1109-18.

20. Kim YJ, Jeon JN, Jang MG, Oh JY, Kwon WS, Jung SK, Yang DC. Ginsenoside profiles and related gene expression during foliation in Panax ginseng Meyer. J Ginseng Res. 2014;38:66 - 72.

21. Bae JK, Kim YJ, Chae HS, Kim DY, Choi HS, Chin YW, Choi YH. Korean red ginseng extract enhances paclitaxel distribution to mammary tumors and its oral bioavailability by P-glycoprotein inhibition. Xenobiotica. 2016;17:1-10. 
22. Lee S, Park JM, Jeong M, Han YM, Go EJ, Ko WJ, Cho JY, Kwon Cl, Hahm KB. Korean red ginseng ameliorated experimental pancreatitis through the inhibition of hydrogen sulfide in mice. Pancreatology. 2016;16:326-36.

23. Singh P, Kim YJ, Wang C, Mathiyalagan R, Farh ME, Yamg DC. Pseudomonas deceptionensis DC5mediated synthesis of extracellular silver nanoparticles. Artif Cell Nanomed B. 2015;44:1-6.

24. Singh P, Kim YJ, Wang C, Mathiyalagan R, Farh ME, Yamg DC. Cardamom fruits as a green resource for facile synthesis of gold and silver nanoparticles and their biological applications. Artif Cell Nanomed B. 2015;44:1-8.

25. Yao H, Li J, Song Y, Zhao H, Wei Z, Li X, Jin Y, Yang B, Jiang J. Synthesis of ginsenoside Re-based carbon dots applied for bioimaging and effective inhibition of cancer cells. Int J Nanomedicine. 2018;13:6249-64.

26. Yuan F, Li S, Fan Z, Meng X, Fan L, Yang S. Shining carbon dots: synthesis and biomedical and optoelectronic applications. Nano Today. 2016;11:565-86.

27. Obaid G, Chambrier I, Cook MJ, Russel DA. Cancer targeting with biomolecules: a comparative study of photodynamic therapy efficacy using antibody or lectin conjugated phthalocyanine-PEG gold nanoparticles. Photochem Photobiol Sci. 2015;14:737-47.

28. Kailasa SK, Bhamore JR, Koduru JR, Park TJ.. . ; Chap. Carbon dots as carriers for the development of controlled drug and gene delivery systems. Biomedical Applications of Nanoparticles. 2019;11:p. 295-317.

29. Rudnickglick S, Coremsalkmon E, Grinberg I, Margel S. Targeted drug delivery of near IR fluorescent doxorubicin-conjugated poly(ethylene glycol) bisphosphonate nanoparticles for diagnosis and therapy of primary and metastatic bone cancer in a mouse model. J Nanobiotechnology. 2016;14:80.

30. Sarkar N, Sahoo G, Das R, Prusty G, Sain SK. Carbon quantum dot tailored calcium alginate hydrogel for $\mathrm{pH}$ responsive controlled delivery of vancomycin. Eur J Pharm Sci. 2017;109:359-71.

31. Bayda S, Hadla M, Palazzolo S, Kumar V, Caligiuri I, Ambros E, Pontoglio E, Agostini M, Tuccinardi T, Benedetti A, Riello P, Canzonieri V, Corona G, Toffoli G, Rizzolio F. Bottom-up synthesis of carbon nanoparticles with higher doxorubicin efficacy. J Control Release. 2017;248:144-52.

32. Mujtaba MA. Hassan KAM, Imran M. Chitosan-Alginate Nanoparticles as a Novel Drug Delivery System for Rutin. Int J Adv Biotechnol Res. 2018;9:1895-903.

33. Nafees S, Mehdi SH, Zafaryab M, Zeya B, Sarwar T, Rizvi MA. Synergistic Interaction of Rutin and Silibinin on Human Colon Cancer Cell Line. Arch Med Res. 2018;49:226-34.

34. Gullon B, Chau TAL, Moreira MT, Lema JM, Eibes G, Rutin. A review on extraction, identification and purification methods, biological activities and approaches to enhance its bioavailability. Trends Food Sci Technol. 2017;67:220-35.

35. Shimada K, Fujikawa K, Yahara K, Nakamura T. Antioxidative properties of xanthan on the autoxidation of soybean oil in cyclodextrin emulsion. J Agric Food Chem. 1992;40:945-8.

36. Ruch RJ, Cheng SJ, Klaunig JE. Prevention of cytotoxicity and inhibition of intercellular communication by antioxidant catechins isolated from Chinese green tea. Carcinogenesis. 
1989;10:1003-8.

37. Vijayalakshmi M, Rukmani V. Ferric reducing anti-oxidant power assay in plant extract. Bangladesh J Pharmacol. 2016;11:570-2.

38. Ahmed D, Khan MM, Saeed R. Comparative Analysis of Phenolics, Flavonoids, and Antioxidant and Antibacterial Potential of Methanolic, Hexanic and Aqueous Extracts from Adiantum caudatum Leaves. Antioxidants. 2015;4:394-409.

39. Sadhukhan P, Saha S, Sinha K, Brahmachari G, Sil PC. Selective Pro-Apoptotic Activity of Novel 3,3'(Aryl/Alkyl-Methylene) Bis(2-Hydroxynaphthalene-1,4-Dione) Derivatives on Human Cancer Cells via the Induction Reactive Oxygen Species. PLoS One. 2016;11:0158694.

40. Sadhukan P, Kundu M, Rana S, Kumar R, Das J, Sil PC. Microwave induced synthesis of ZnO nanorods and their efficacy as a drug carrier with profound anticancer and antibacterial properties. Toxicol Rep. 2019;6:176-85.

41. Wang D, Markus J, Kim YJ, Wang C, Pérez ZEJ, Ahn S, Aceituno VC, Mathiyalagan R, Yang DC. Coalescence of functional gold and monodisperse silver nanoparticles mediated by black Panax ginseng Meyer root extract. Int J Nanomedicine. 2016;11:6621-34.

42. Pecora R. Dynamic light scattering measurement of nanometer particles in liquids. J Nanoparticle Res. 2000;2:123-31.

43. Sun D, Ban R, Zhang PH, Wu GH, Zhang JR, Zhu JJ. Hair fiber as a precursor for synthesizing of sulfur-and nitrogen-co-doped carbon dots with tunable luminescence properties. Carbon. 2013;64:424-34.

44. Das K, Kalita B. Design and evaluation of phyto-phospholipid complexes (Phytosomes) of rutin for transdermal application. J Appl Pharm Sci. 2014;4:051-7.

45. Thakur M, Pandey S, Mewada A, Patil V, Khade M, Goshi E, et al. Antibiotic conjugated fluorescent carbon dots as a theranostic agent for controlled drug release, bioimaging, and enhanced antimicrobial activity. J Drug Deliv. 2014;2014:282193.

46. Sila FZ, Bika ZD, Simonyi M. Probing the binding of the flavonoid, quercetin to human serum albumin by circular dichroism, electronic absorption spectroscopy and molecular modelling methods. Biochem Pharmacol. 2003;65:447.

47. Lee KH, Kim WJ, Kim HJ, Kim KT, Paik HD. Antibacterial activity of Ginseng (Panax ginseng CA Meyer) stems-leaves extract produced by subcritical water extraction. Int J Food Sci Technol. 2013;48:947-953.

48. Das J, Sarkar A, Sil PC. Hexavalent chromium induces apoptosis in human liver (HepG2) cells via redox imbalance. Toxicol Rep. 2015;2:600-8.

49. Mohamed K, Zine K, Fahima K, Abdelfattah E, Sharifudin SM, Duduku KK, Mohamed K. NiO nanoparticles induce cytotoxicity mediated through ROS generation and impairing the antioxidant defense in the human lung epithelial cells (A549): preventive effect of Pistacia lentiscus essential oil. Toxicol Rep. 2018;5:480-8. 
Figures

(a)

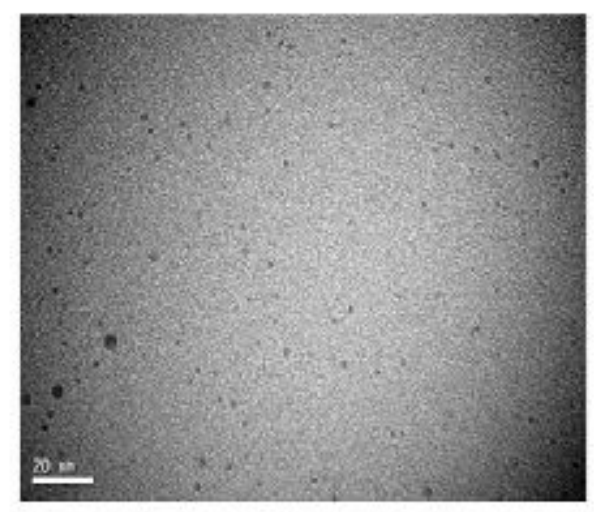

(b)

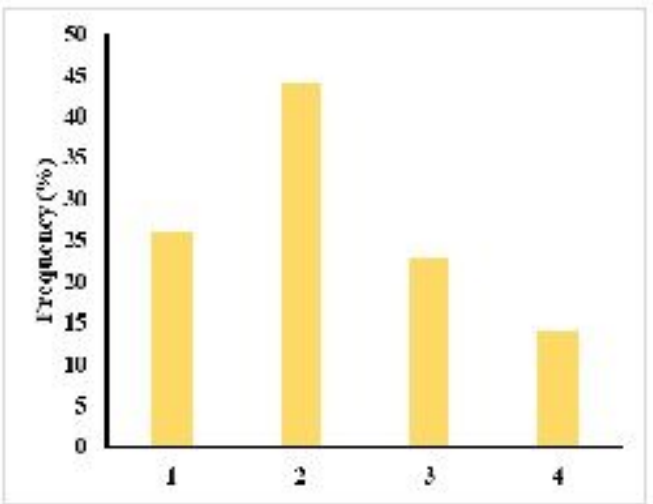

(c)

(d)
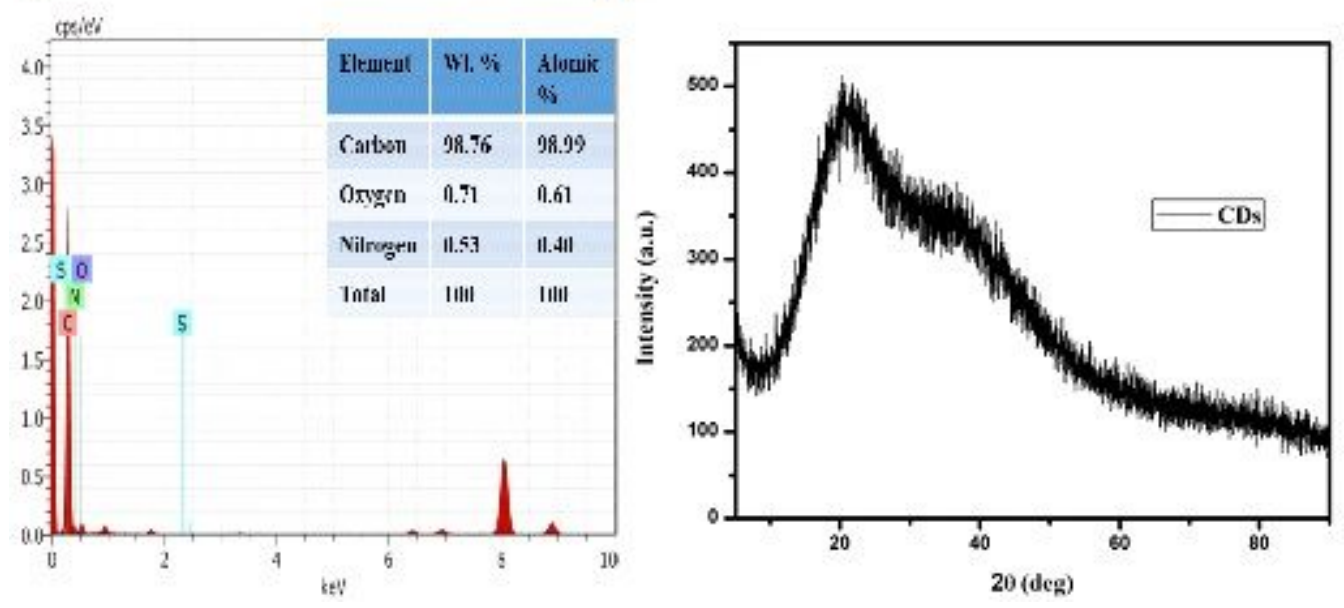

Figure 1

(a) TEM, (b) Size Distribution, (c) EDX, and (d) XRD analysis of the CDs 
(a)

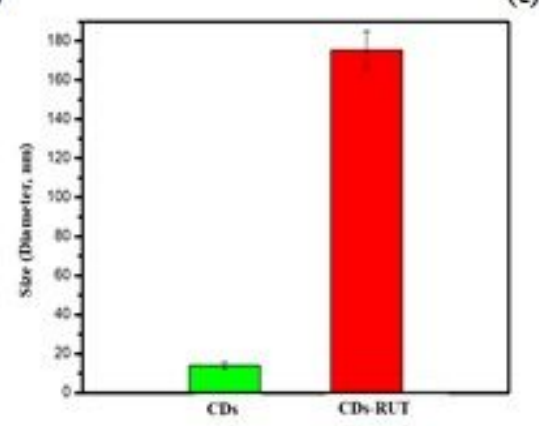

(c)

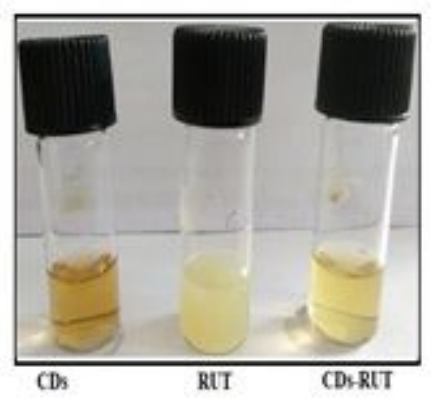

(b)

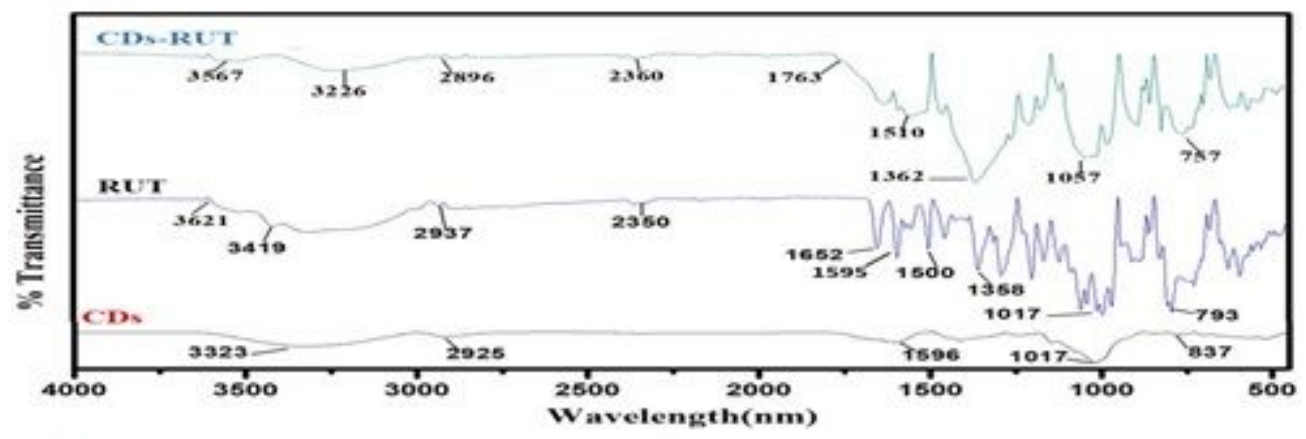

(d)

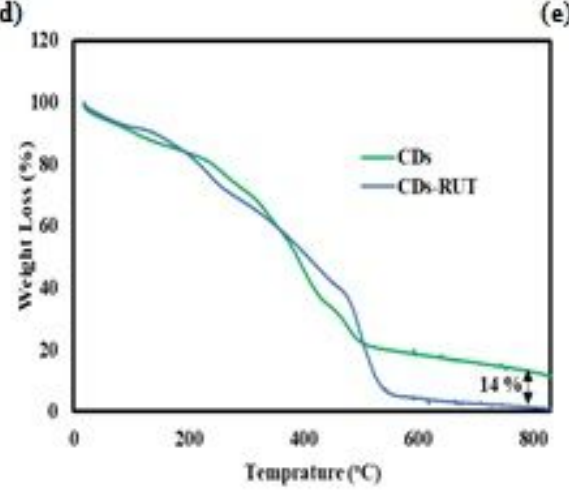

(e)

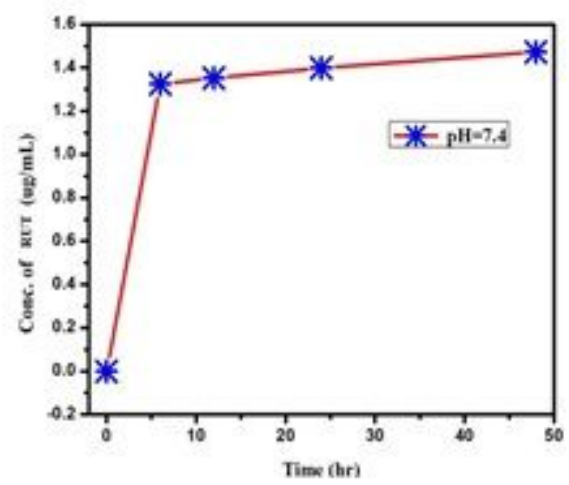

Figure 2

(a) DLS and (b) FTIR spectra of CDs, RUT and CDs-RUT; (c) Photographs of the aqueous solution of CDs, RUT and CDs-RUT, (d) TGA analysis of CDs and CDs-RUT (e) Time dependent drug release from CDs-RUT. 
(a)

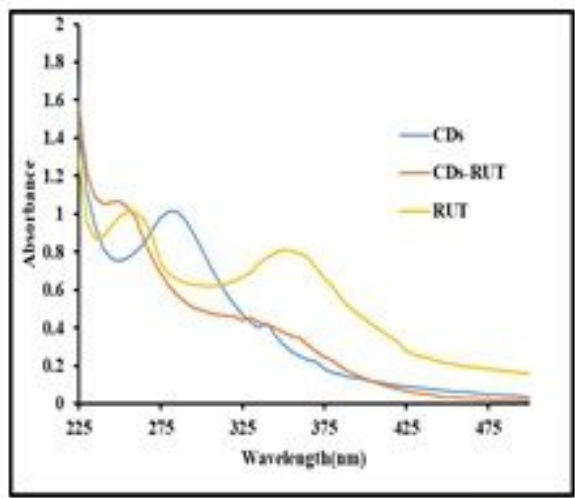

(c)

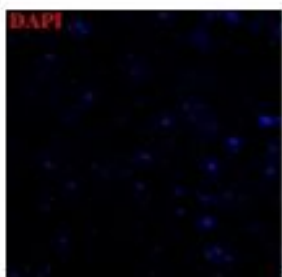

Bright, Viela

(b)

(d)

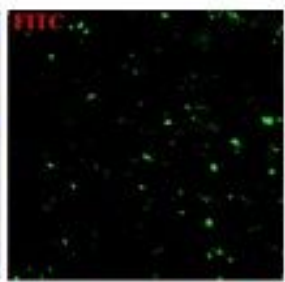

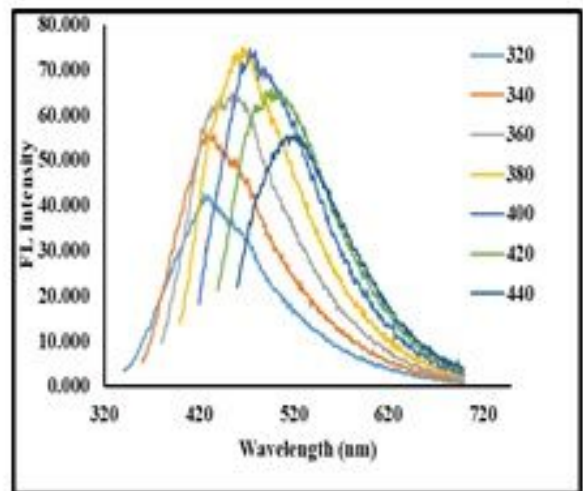

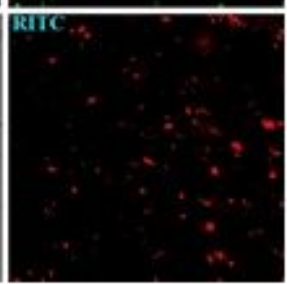

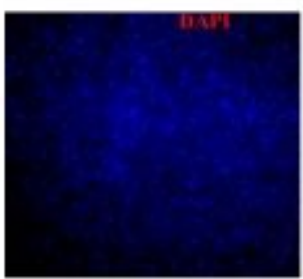

Bright Fich

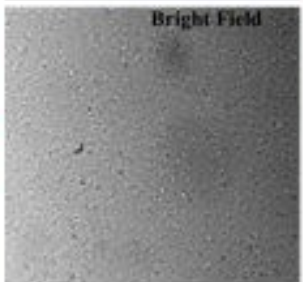

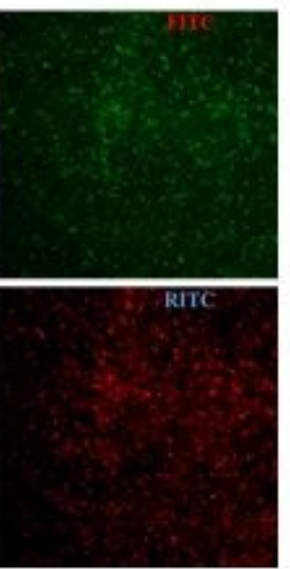

Figure 3

(a) UV-Vis and (b) Fluorescence spectra of spectra of CDs, RUT and CDs-RUT; (c) Fluorescence microscopy images of CDs at 20X magnification; (d) Fluorescence microscopy images of CDs uptake in E. coli cells. 

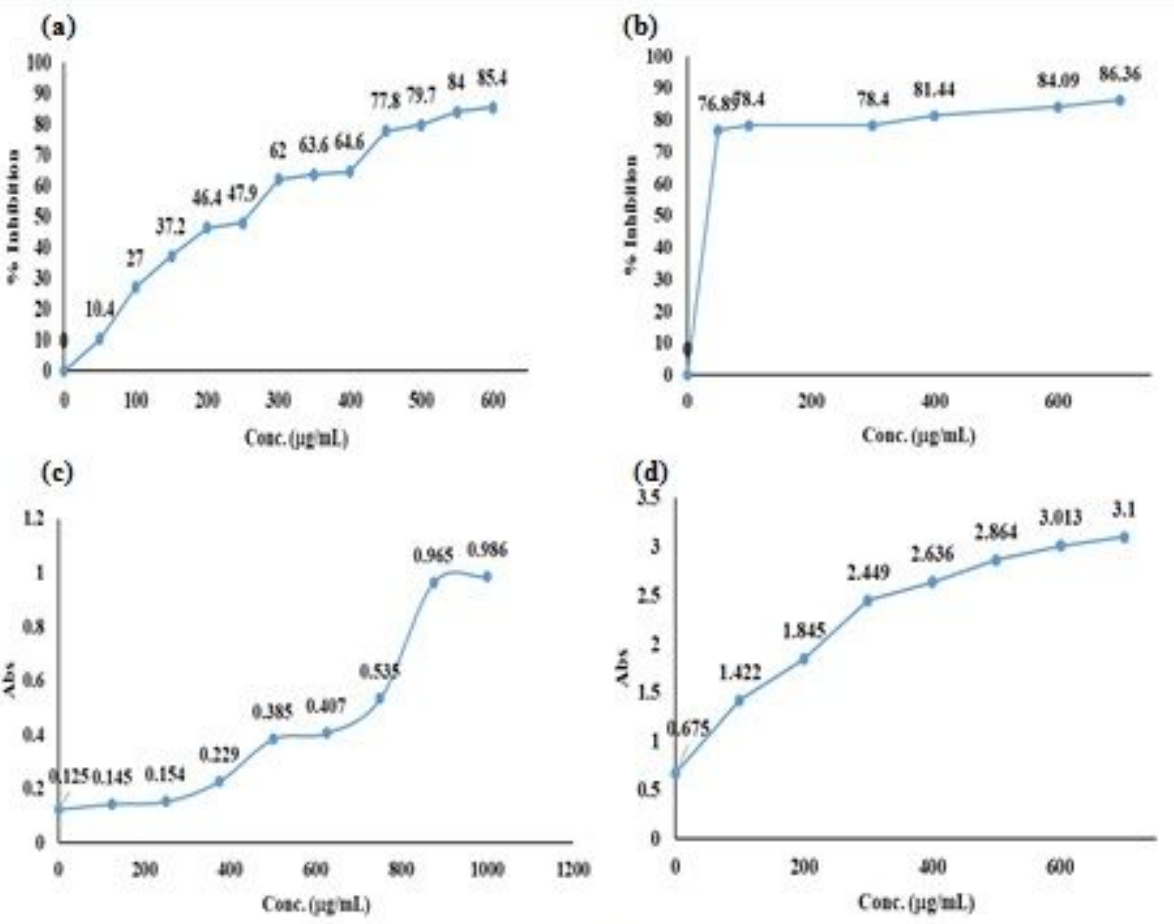

(e)

(f)
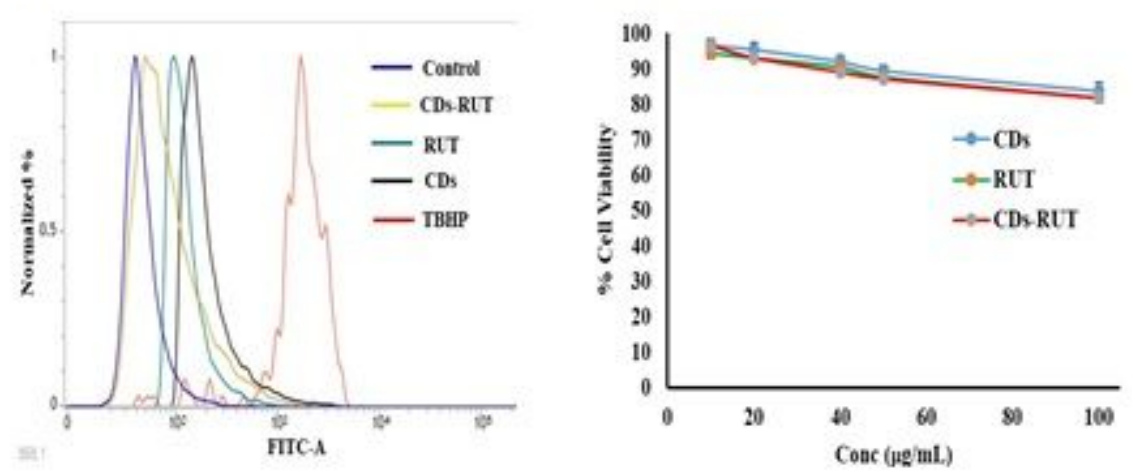

Figure 4

(a) DPPH Assay (b) H2O2 assay (c) Ferric reducing power assay (d) Ferric reducing anti-oxidant potential of CDs; (e) Intracellular ROS levels (f) Cell Viability assay. 
(a)

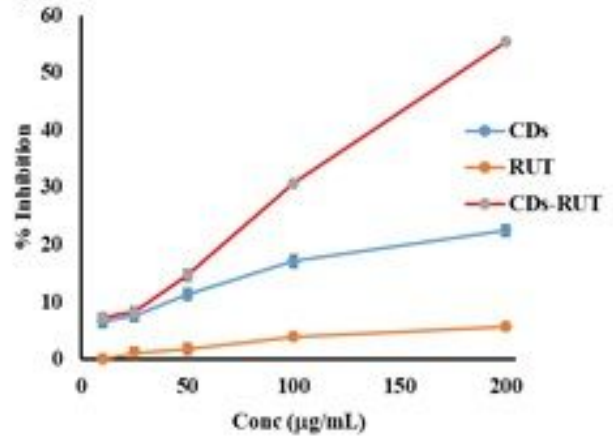

(b)

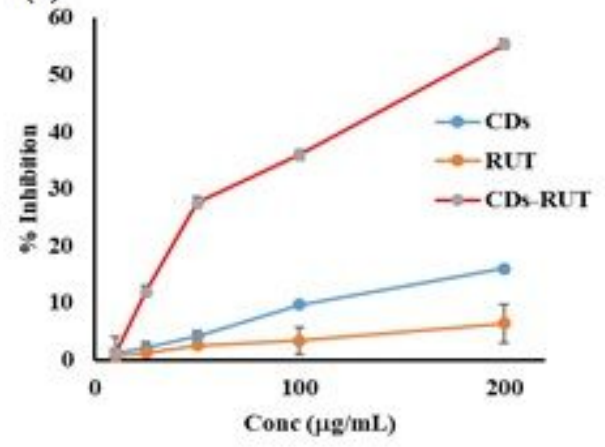

(c)

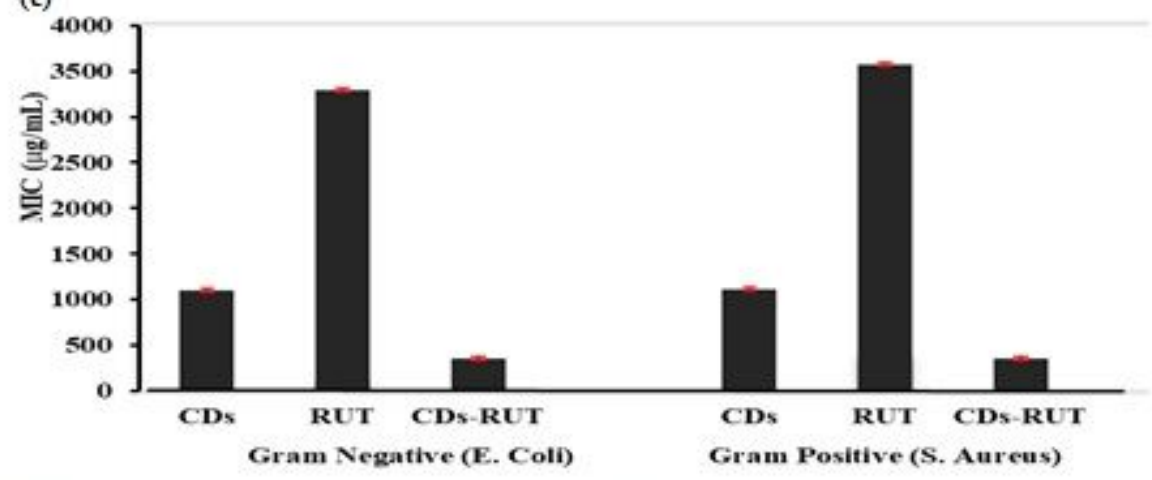

(d)

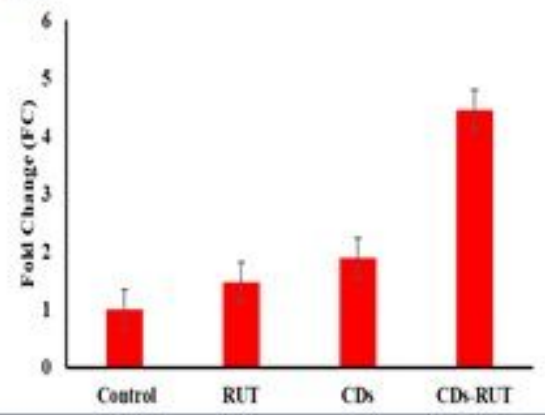

(e)

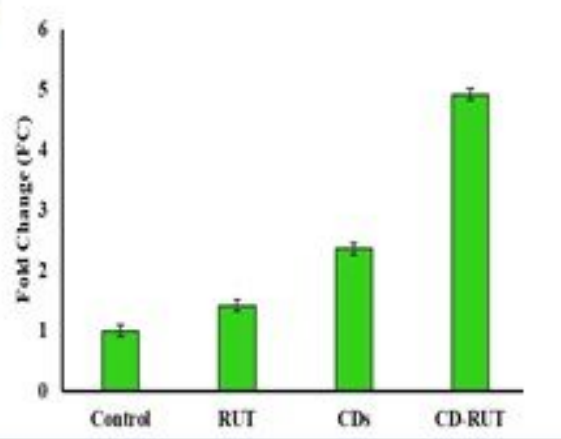

Figure 5

(a) \& (b) antibacterial activities of CDs, RUT and CDs-RUT in gram positive (S. aureus) and gram negative (E. coli) respectively; (c) Minimum Inhibitory Concentrartion (MIC) of CDs, RUT and CDs-RUT in E. coli and S. aureus bacterial cells; (d) \& (e) ROS levels in terms of Fold increase in gram positive (S. aureus) and gram negative (E. coli) bacteria respectively. 

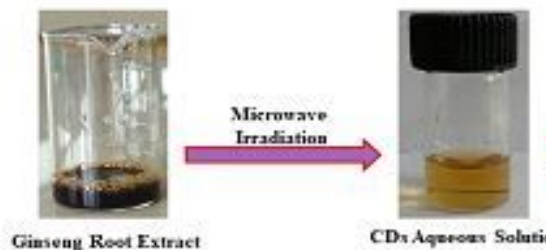

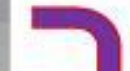

Giaseal Reot Extrac

CDs Aqueoens Solution
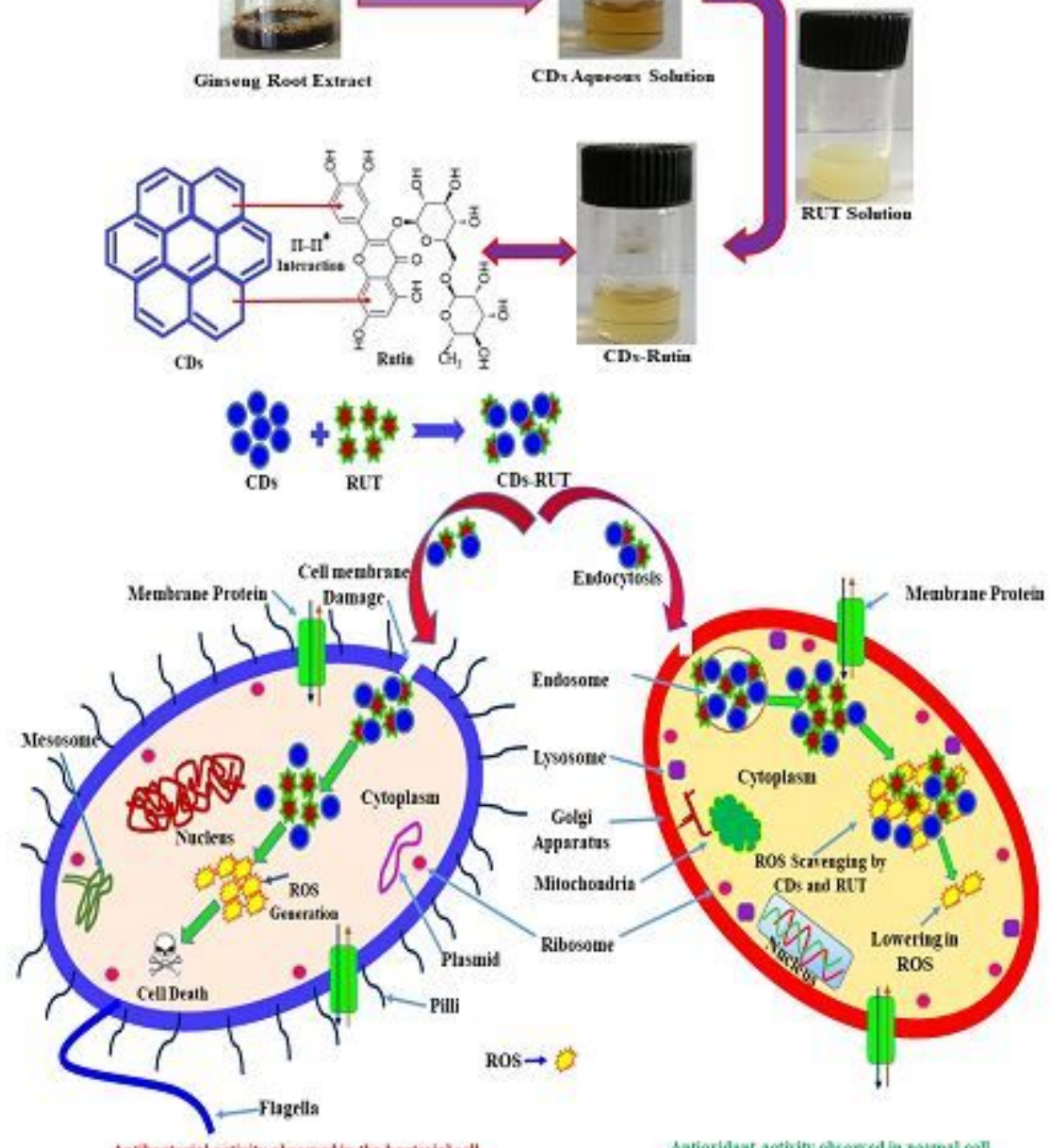

Aathacterial acthity obsened in the bacterialcell

Aatiosidast actinity observed in botmal cell

Figure 6

A schematic presentation for the synthesis procedure and applications of nanohybrids 